\title{
Detection of Ascaris lumbricoides by Capsule Endoscopy
}

\author{
Pavel P. Poliakov1, Anar Y. Alimetov², Alexandr V. Onopriev², Andrey V. Avakimyan³, Azamat Kh. Kade1
}

\author{
1Department of Pathophysiology, Kuban State Medical University, Krasnodar, Russia \\ ${ }^{2}$ Department of Postgraduate Surgery, Kuban State Medical University, Krasnodar, Russia \\ ${ }^{3}$ Klinika-A OOO (Limited Liability Company), Krasnodar, Russia
}

\begin{abstract}
A 47-year-old Caucasian woman complained of abdominal discomfort and general weakness. Her medical history indicated travels to ascariasis-endemic areas. Her hemoglobin level was 7.6 $\mathrm{g} / \mathrm{dL}$. Esophagogastroduodenoscopy revealed no evidence of active bleeding and colonoscopy revealed no pathology.

Capsule endoscopy revealed a live helminth in the terminal ileum, which was identified as Ascaris lumbricoides (Figure 1). Written informed consent was obtained from the patient. There were no
\end{abstract}

adverse effects or complications of the procedure. Albendazole was prescribed to the patient.

A. lumbricoides is the most common soil-transmitted helminth, infecting more than 800 million patients globally (1). An increase in global migration and travel contributes to the prevalence of ascariasis, as well as other soil-transmitted helminth infections, in non-endemic regions. An absence of travel to endemic regions in an individual's medical history does not exclude the possibility of
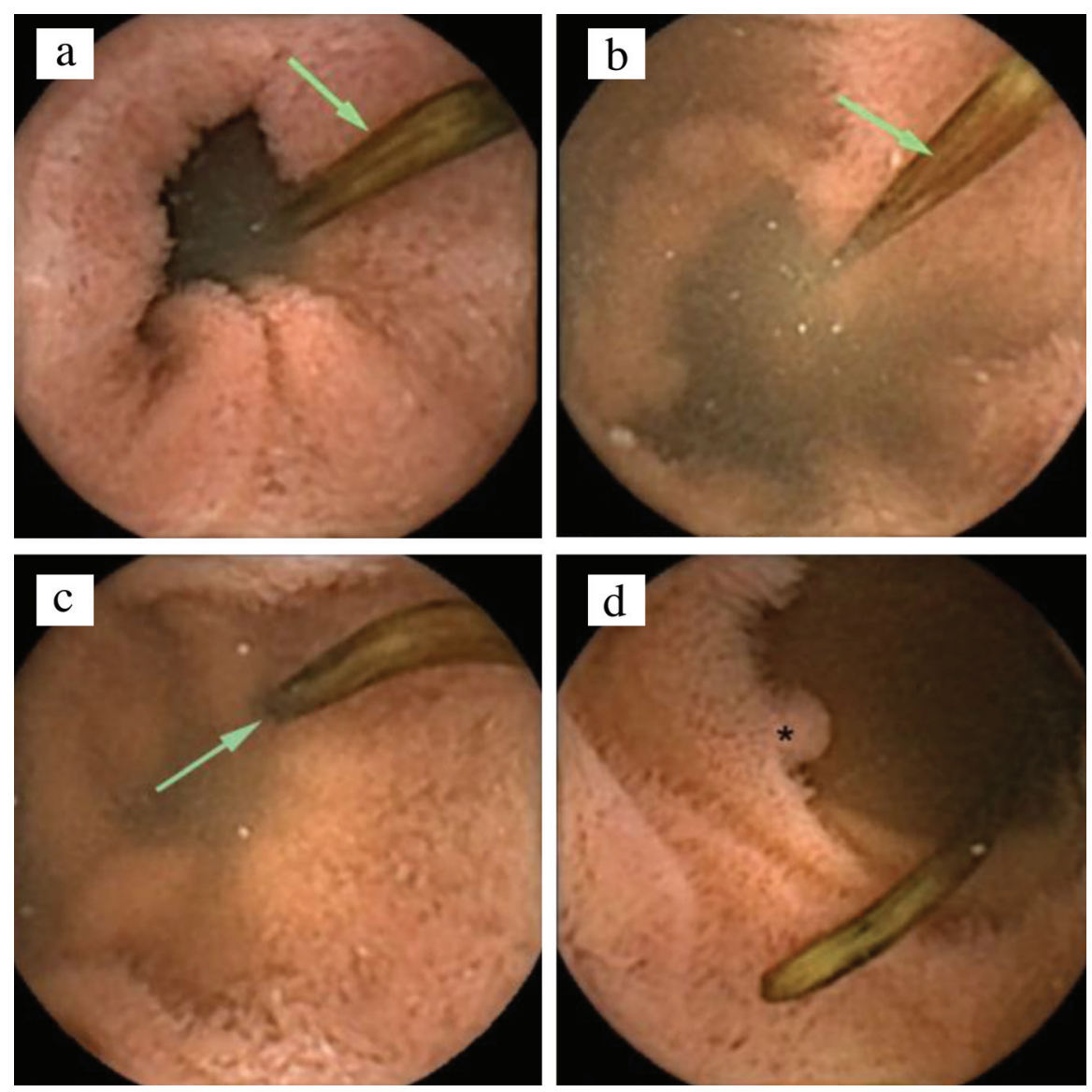

FIG. 1. a-d. Live helminth (arrow) in bowel lumen (a-c). Pseudopolyp (asterisk) (d).

Address for Correspondence: Pavel P. Poliakov, Department of Pathophysiology, Kuban State Medical University, Krasnodar, Russia

e-mail: palpal.p@yandex.ruＯRCID: orcid.org/0000-0002-9532-0626

Received: 9 October $2018 \quad$ Accepted: 21 December 2018 • DOI: 10.4274/balkanmedj.galenos.2018.2018.1548

Available at www.balkanmedicaljournal.org

Cite this article as:

Poliakov PP, Alimetov AY, Onopriev AV, Avakimyan AV, Kade A. Detection of Ascaris lumbricoides by Capsule Endoscopy. Balkan Med J 2019;36:143-4

${ }^{\circ}$ Copyright 2019 by Trakya University Faculty of Medicine / The Balkan Medical Journal published by Galenos Publishing House. 
ascariasis. This is because in addition to A. lumbricoides, humans can also be infected with Ascaris suum, which typically infects pigs (there are arguments in favor of these nematodes belonging to the same species) $(1,2)$.

Three main pathogenic mechanisms underlie the numerous manifestations of ascariasis that resemble the symptoms of various diseases. Migration of larvae into the lungs damages the blood-air barrier (causing hemoptysis) and induces type I hypersensitivity reaction (eosinophilia and Löffler syndrome). Larvae mature into adult helminth in the intestine resulting in abdominal pain, damage to liver and pancreas, and malabsorption. Asymptomatic cases are also common (1-4).

Soil-transmitted helminth infections should be considered when conducting differential diagnosis in patients with concealed gastrointestinal bleeding and anemia that cannot be explained by other causes $(2,3)$. In such cases, capsule endoscopy offers the ability to visualize the intestinal mucosa.

Conflict of Interest: No conflict of interest was declared by the authors.

\section{REFERENCES}

1. Lamberton PH, Jourdan PM. Human Ascariasis: Diagnostics Update. Curr Trop Med Rep 2015;2:189-200

2. Brieau B, Loulergue P, Coriat R. Ascariasis seen by videocapsule endoscopy. Dig Endosc 2018;30:273-4

3. Ghosh G, Shah S, Maltz C. Ascariasis Diagnosed by Wireless Capsule Endoscopy. Clin Gastroenterol Hepatol 2018;16:A23.

4. Yamashita ET, Takahashi W, Kuwashima DY, Langoni TR, Costa-Genzini A. Diagnosis of Ascaris lumbricoides infection using capsule endoscopy. World J Gastrointest Endosc 2013;5:189-90. 